\title{
Sobre las víctimas con respecto a la implementación de modelos de justicia transicional en países latinoamericanos: perspectivas en cinco entrevistas realizadas a víctimas en Colombia, Argentina y Perú*
}

\author{
About the victims related to the implementation of the model of \\ transitional justice in Latin American countries: Perspectives of five \\ interviews carried out with victims in Colombia, Argentina and Peru
}

\section{Resumen}

Este texto tiene como finalidad presentar el ejercicio de documentación sobre las perspectivas de cinco víctimas de los Estados de Colombia, Argentina y Perú sobre la implementación de los modelos de justicia transicional en sus países. Uno de los propósitos del documento es evidenciar algunas lecturas, desde el rol de víctima, que surgen con relación a la puesta en práctica de estos modelos de justicia transicional, a la luz de las construcciones que desde el discurso existen sobre la materia,. Por ejemplo: la versión oficial del Estado, los estudios académicos, las producciones normativas y las relaciones políticas globales. El documento se estructura en tres partes, cada una hace referencia a un Estado en el que se desarrolla un panorama general del contexto de violencia, sea conflicto armado o dictadura, también se hace mención al tipo de modelo de justicia transicional y posteriormente, se hace referencia a las entrevistas realizadas a las víctimas con relación al tema.

Palabras clave: modelo de justicia transicional, perspectivas de implementación, víctimas.

* Artículo de reflexión Programa de Especialización en Educación en Derechos Humanos de Unicatólica.

** Investigadora en Educación, IEO Santa Rosa de Cali y Escuela Nacional del Deporte, magíster en Educación Superior de la Universidad Santiago de Cali. Correo electrónico: sarizabaletad@endeporte.edu.co. Orcid: https://orcid.org/0000-0001-6255-009X

*** Abogadade la Universidad Santiago de Cali, Magíster en Literaturas latinoamericanas y colombianas Universidad del Valle. Docente en Unicatólica. EDUCARTE de Unicatólica. Cali-Colombia. Correo electrónico: jmarias@unicatolica.edu.co. ORCID: https://orcid.org/0000-0001-6423-1658 


\section{Abstract}

This text aims to present a documentation exercise about the perspectives of five victims in Colombia, Argentina and Peru regarding the implementation of the models of transitional justice in each country. One of the goals is to evidence -from a victim role- some readings that arise related to the execution of these models of transitional justice, in the light of the constructions on the matter, such as the official version of the country, academic studies, production of regulations, and global and political relations. This document is structured in three sections, each one makes reference to a country in which a comprehensive view of the violence context was held, whether armed coflict or dictatorship. -the model of transitional justice is mentioned as well, and subsequently, this paper refers to interviews carried out with victims regarding this issue.

Keywords: model of transitional justice, implementation prospects, victims.

\section{Introducción}

El Centro Internacional para la Justicia Transicional (ICT) por suus siglas en inglés) es una organización que coadyuva a los Estados en los procesos que enfrentan para la implementación de una justicia en periodos de transición, concibe la justicia transicional como la herramienta que le permite a los países que se encuentran en una situación de conflicto y represión hacer uso de una forma de justicia, por fuera de la justicia convencional para: enfrentar violaciones masivas de derechos humanos, establecer procesos especiales para que los actores del conflicto asuman sus responsabilidades, poner en práctica formas de reparación integral para las víctimas y hacer efectivas garantías de no repetición. En ese sentido, en sus estudios sobre los enfoques de los modelos de justicia transicional, el Centro Internacional para la Justicia Transicional menciona que deben estar presentes los siguientes: reformas jurídicas e institucionales, procesos de esclarecimiento de la verdad, procesos penales y reparaciones diversas, que pueden variar de acuerdo con las particularidades de cada situación (ICT), 2018).

Hablar de una justicia transicional integral implica no obviar la importancia de hacer un análisis de contexto, es decir, de las condiciones específicas de los territorios y de las comunidades y de posibilitar escenarios de participación que permitan ampliar el espectro frente a la diversidad de voces (sectores populares, víctimas del conflicto, grupos armados ilegales, grupos armados oficiales e instituciones jurídicas y políticas); esto permitirá la puesta en práctica de intervenciones adecuadas que respondan a las necesidades y objetivos de este tipo de justicia de transición. Algunos de los objetivos de la justicia transicional son el reconocimiento de la dignidad humana, la reparación, promoción de resoluciones duraderas de los conflictos y el fomento de la reconciliación, por ende, las víctimas tienen un papel fundamental en ella.

Las víctimas de los conflictos armados son individuales o colectivas, depende del daño o perjuicio que se les haya ocasionado por diversas formas de ejercicio de la violencia, por ejemplo: desplazamiento forzado, genocidio, torturas, secuestro, masacres, vulneración a su patrimonio cultural y costumbres, desapariciones forzadas, actos de agresión sexual que se traducen en la plena vulneración a la dignidad humana y a los derechos humanos, debido a conductas cometidas por grupos armados ilegales, el Estado y otros sectores paraestatales. Las víctimas del conflicto armado representan un rol importante en cualquier proceso de implementación de un modelo de justicia transicional porque eso posibilita poner en práctica: las acciones encaminadas a conocer la verdad; el ejercicio de la justicia; hacer efectivo cualquier mecanismo que permita la reparación integraly asegurar las garantías de no repetición con miras a desarrollar acciones encaminadas a una verdadera reconciliación. 


\section{Cinco perspectivas de algunas víctimas de Argentina, Perú y Colombia}

Se reconoce a las víctimas como uno de los actores más importantes a la hora de concebir, planear, construir, implementar y poner en práctica un modelo de justicia transicional integral porque se parte del análisis de su contexto y de la creación de escenarios que permitan su participación activa, siendo uno de los objetivos de este tipo de justicia transitoria. Por esa razón, los Estados que se han enfrentado a situaciones de conflicto y represión han adoptado modelos de justicia transicional acordes a sus particularidades. Si bien los enfoques de la justicia transicional son diversos, cada país - de acuerdo con sus intereses- le ha dado prioridad a las reformas jurídicas e institucionales o a los juicios penales, al esclarecimiento de la verdad (Comisiones de la Verdad), también a las diversas formas de reparación desde una perspectiva simbólico-formal, pero esto no es suficiente, es necesario cuestionarse sobre el aspecto real-material de estos modelos de justicia transicional, es decir, lo que en un plano práctico pueda determinar su efectividad o por lo menos, sus efectos; es aquí que la voz de las víctimas cobra relevancia.

En ese sentido, un ejercicio investigativo sobre el tema permitiría ofrecer otra lectura sobre los modelos de justicia transicional, en este caso, desde la perspectiva de las víctimas del conflicto armado. Por tal razón se realizó una estancia investigativa en Argentina y Perú, con el objetivo de conocer la experiencia de algunas de las víctimas de la dictadura argentina y del conflicto armado en Perú con Sendero Luminoso, con la finalidad de hacer un ejercicio reflexivo frente a los modelos de justicia transicional de estos Estados, incluyendo al Estado colombiano. La técnica utilizada fue una entrevista semiestructurada, de carácter experiencial, que tenía como base en preguntas que dan cuenta de la historia de vida de los entrevistados con relación al conflicto, su condición de víctima en el marco del conflicto y el impacto de la implementación del modelo de justicia transicional para las víctimas.
Se apela a la ética investigativa en materia del manejo de la información y de la identidad de los participantes, no se revelan sus nombres y solo se hace uso expreso, de la información que fue autorizada para publicación.

\section{Conflicto armado en Colombia, Argentina y Perú}

Las causas de los conflictos en los países latinoamericanos Argentina, Perú y Colombia han sido diferentes: dictaduras militares, disputas del poder entre los gobiernos militares y constitucionales, hasta conflictos armados entre grupos políticos, grupos al margen de la ley, fuerzas militares, representantes del gobierno, narcotraficantes y civiles, lo cual indica que cada uno tiene sus particularidades y formas de desarrollo.

El brote de estas situaciones de violencia y conflicto parece una paradoja en los países latinoamericanos cuando son ricos en biodiversidad, recursos no renovables como el petróleo, minerales como el oro y tierras fértiles que se han utilizado para la siembra de cultivos ilícitos como coca, amapola y marihuana, también poseen una diversidad cultural y étnica. Estos son algunos de los factores que han hecho de los territorios, escenarios de explotación masiva por parte de las multinacionales, grupos ilegales y narcotraficantes, por lo cual se convierten en uno de los desencadenantes del conflicto que vulnera los derechos de las comunidades. Dicho conflicto por el territorio y sus recursos remite a hechos víctimizantes como el despojo de la tierra y el desplazamiento masivo de quienes lo habitan.

Desde la praxis investigativa y desde algunas de las voces de víctimas directas del conflicto en Argentina, Perú y Colombia fue posible rastrear las secuelas que ha dejado: la desconfianza por la institucionalidad y el fuerte impacto emocional que ha quedado en la psique de diferentes generaciones de víctimas directas e indirectas del conflicto. Es 
por ello por lo que vale la pena analizar sus lecturas en calidad de víctimas en relación con la capacidad institucional del Estado para la implementación de los respectivos modelos de justicia transicional.

\section{Algunas víctimas del conflicto en Argentina}

La última dictadura cívico-militar que se dio en Argentina entre 1976 y 1983, que de acuerdo con lo expuesto por Patierno y Martino (2016), también se denominó Proceso de Reorganización Nacional y se caracterizó porque los militares de las Fuerzas Armadas ejercieron el poder por medio de Juntas Militares como resultado del golpe de Estado del 24 de marzo de 1976.

En este período de siete años se recrudeció la violencia por un tipo de terrorismo de Estado en el que alrededor de más de 30.000 personas fueron víctimas de: privaciones ilegales de la libertad; desapariciones forzadas; persecuciones políticas; torturas; desplazamientos forzados; homicidios; exilios forzados; masacres, entre otras conductas que vulneraron los derechos humanos y que fueron consideradas crímenes de lesa humanidad. Formó parte activa de estas acciones el conocido Plan Cóndor, una operación de cooperación entre las cúpulas militares de algunos Estados de Sur América para perseguir, asesinar y desaparecer personas y colectivos que amenazaran la política económica neoliberal, entre los Estados participantes se encontraban Estados Unidos de Norte América, Argentina, Brasil, Chile, Uruguay, Perú, Ecuador, Colombia, entre otros.

Lo anterior permeó todas las esferas sociales, política cultural y educativa que controlaron violentamente la producción científica, cultural y artística mediante la censura; hubo corrupción camuflada en actividades deportivas y recreativas como la Copa Mundial de Fútbol de la FIFA de 1978; se implementó una política neoliberal con gran inversión extranjera y políticas laborales que prohibieron el ejercicio de derechos como aquel de hacer huelgas y conformar, asistir o ser miembro de asociaciones sindicales.

En cuanto a actos relacionados con un proceso de justicia transicional, Argentina creó la Comisión Nacional sobre la Desaparición de Personas; juicios penales denominados Juicio a las Juntas; reformas jurídicas al Código Penal; formas de reparación colectiva como el Día Nacional de la Memoria por la Verdad y la Justicia.

Con esta introducción se pretende contextualizar el lugar y la razón de ser de las entrevistas realizadas a algunas de las víctimas de la dictadura militar en Argentina.

De las personas entrevistadas, se seleccionaron dos casos presentados aquí a manera de narración. Las citas utilizadas obedecen expresamente a lo manifestado y autorizado para develar por las víctimas, que se denominan entrevistado 1 y entrevistado 2.

\section{Entrevistado 1}

Hija de un militar, un oficial del ejército argentino que fue acusado y judicializado debido a la dictadura militar en Argentina. Actualmente, su padre tiene 87 años y no se encuentra muy bien de salud. Ella estudió abogacía, trabaja hace muchos años en el poder judicial; 28 años ejerció la defensa de su padre en juicios penales en calidad de abogada, pero al formar parte del poder judicial, tuvo impedimento por el tipo de cargo público para seguir asumiendo la defensa de su padre. Tiempo después, renunció al cargo y se dedicó a ejercer el Derecho como abogada. En vista de la experiencia con su padre, se ha dedicado a defender a oficiales del ejército argentino a quienes se les han imputado delitos relacionados con la dictadura militar $y$ otros asuntos. En este ejercicio profesional ha sido testigo del inicio, desarrollo, cierre, revisión y reapertura de este tipo de procesos. Concluyó la entrevista manifestando lo siguiente: 
La realidad con mi padre fue que no hubo un mecanismo de esclarecimiento de la verdad, él fue juzgado injustamente y se le vulneraron los derechos. De la misma manera, como hijos fuimos víctimas del conflicto y así como estoy yo, están muchos argentinos, sin un proceso de reparación integral, aunque se dio una reparación económica, no se dio un apoyo psicosocial para abordar el problema. Hay muchos hijos buscando a sus padres y padres buscando a sus hijos. Hay mucho dolor entre los argentinos y por supuesto, esto se traduce en violencia. (entrevista personal, Buenos Aires, Argentina, 20 de septiembre del 2017)

\section{Entrevistado 2}

Abogado penalista, dejó el ejercicio de la profesión hace varios años. En el 2005 detuvieron a su padre, este ocupaba un cargo de gobierno antes del problema militar de 1976. Lo acusaron y judicializaron en un Tribunal, pero le vulneraron el derecho al debido proceso porque no le llegaron a dictar sentencia, se le privó de la libertad arbitrariamente con medida extramural (domiciliaria). A los 40 años de estar privado de la libertad, le revocaron la restricción domiciliaria que tenía y fue recluido en un centro penitenciario y carcelario. Para ese entonces, ya era un paciente cardíaco, tenía cáncer, tenía alzhéimer y no tenía movilidad en las piernas, pese a su situación crítica, le revocaron la medida de detención domiciliaria y lo llevaron a un penal, los médicos del servicio penitenciario no lo quisieron recibir y su salud se fue deteriorando hasta morir. Esto significó mucho para él como hijo y víctima del conflicto, su padre murió el día en que se conmemora a las víctimas en Argentina, y desde ese momento dedica gran parte de su vida personal y profesional a asistir gratuitamente a militares y policías que están detenidos por estos hechos ocurridos hace 40 años.

Él afirma que todo esto lo sensibiliza mucho -lo expresa con dolor- estudió y se formó bajo principios y reglas que han sido sistemáticamente violadas por el Estado argentino en lo que respecta a la administración de justicia en estos casos. Hoy en día se dedica a estudiar todo el fenómeno de la violencia en la década de 1970 en su país y en Latinoamérica, en especial, lo relacionado con los efectos del conflicto armado y la Dictadura. Ante esto expresa:

De lo que he estudiado y consultado, lo que ha ocurrido en Latinoamérica durante los años 70, en los años luego de la Segunda Guerra Mundial se vivió una guerra que le llamaron la Guerra Fría, entre las dos grandes potencias del norte, la Unión Soviética y Estados Unidos, y empezaron con una técnica de disuasión que se llama congetinidad [sic], que es armarse de forma tal que el contrincante que va a ser destruido llega a poner en riesgo su propio territorio, y para lo cual hay un interés marcado por algún recurso de expropiación. Con respecto a la guerra, nosotros confundimos guerra con el combate; el combate es lo que caracteriza a los militares, es el salpullido en las piernas, es lo que se ve, pero en realidad el conflicto fractura el territorio por partes y tiene una línea que es subterránea y tiene balance sociopolítico. Lo que se ha visto es que esas guerras tuvieron diversas soluciones en Argentina, pues la reacción fue que Estados Unidos preparó las fuerzas armadas del continente en la segunda escuela de las Américas para enfrentarse a una guerra que ellos no conocían, ya no importaba la toma sino que ibas a luchar contra un enemigo identificado con uniforme, que iba a estar dentro de su propia población vestido de civil, identificado como uno más con la típica crueldad que tiene la guerra civil, que es mucho peor que la guerra entre dos países. Eso ocurrió en todo el continente con las organizaciones; aquella revolución que aportó Cuba generó múltiples movimientos guerrilleros, y en todo el sur, los ejércitos de Perú, de Bolivia, de Paraguay, de 
Uruguay, de Argentina, de Chile, tuvieron una reacción. En Perú y en Colombia se evidencia una reacción democrática mucho mayor que en todo el sur, con excepción de Chile, Paraguay, Uruguay, Argentina, que tienen muchos golpes de Estado, muchos militantes que hicieron parte de nuestra cultura y que experimentaron la guerra, continuaron y no acabaron con esto. En Perú y Colombia continuó el conflicto armado, con millones de víctimas que tienen de esta conflagración y que ya tomó intereses económicos que incluso involucraron otros actores, como los narcotraficantes y las multinacionales, para explotar determinado territorio generando hechos victimizantes y violentos. (entrevista personal, Buenos Aires, Argentina, 20 de septiembre del 2017)

El entrevistado 2 afirmó que nosotros -en referencia a los países latinoamericanos-somos países jóvenes y apasionados por las juventudes, así que desde la década de 1970 hay una mínima presencia de movimientos en las organizaciones de derechos humanos y se han querido apropiar del tema por el hecho de ser derechos humanos, han creído que esta puede ser la solución, pero sin tener en cuenta otra alternativa desde un verdadero modelo de justicia transicional: la restauración de la justicia, la reconciliación, el mantenimiento de la paz... y en ese sentido, no hay una conciencia en Argentina en lo que respecta a los mecanismos de justicia, a esto le llamaron juicios de venganza porque son juicios en contra de las fuerzas armadas y de seguridad sin permitirles la posibilidad de que ellos se defiendan, fue la aplicación de un derecho penal que vulneró los derechos procesales y constitucionales de los acusados porque fueron condenados a cadena perpetua sea el cabo, el sargento o el capitán:

[...] en un juicio donde hay un agente civil de inteligencia o un subteniente, que tenía 19 años y el ministro del interior y un general, en el mismo juicio y los condenan a todos a cadena perpetua con presiones muy grandes hacia los jueces, aquí no hubo, ni hay justicia transicional. No hay ningún organismo de peso de los derechos humanos que asuman la paz desde un enfoque restaurativo, poco confiables como para exigir siquiera esclarecer algún acto de arrepentimiento, cualquier persona que ha admitido alguna culpabilidad. (entrevista personal, Buenos Aires, Argentina, 20 de septiembre del 2017)

\section{Algunas entrevistas realizadas a víctimas del conflicto en Perú}

El Partido comunista del Perú Sendero Luminoso (PCP-SL), surgió a principios de la década de 1980 en Perú, fue catalogado como un grupo terrorista y genocida por el Estado peruano. Según lo estudiado por el United States Institute for Peace (USIP) en 2017, Sendero Luminoso tenía una estructura militar: fuerza principal, local y de base. A partir de las acciones de Sendero Luminoso, en 1982 el gobierno peruano declaró el estado de emergencia en el departamento de Ayacucho, en el que asumieron el control las fuerzas armadas y se restringieron los derechos civiles y políticos de la población.

Estas medidas incrementaron los índices de violencia porque tanto los militares como Sendero Luminoso cometieron conductas como: masacres, homicidios, desapariciones forzadas, militarización de los territorios; desplazamiento forzado de las comunidades; secuestros, espionaje, entre otros; a esto se le denominó el conflicto armado interno del Perú, se estimó un promedio de 69.280 personas entre muertos y desaparecidos. En Perú se instauró la Comisión de la Verdad y de la Reconciliación que tuvo como finalidad investigar todos los actos violentos acaecidos entre 1980 y el 2000, el resultado fue un Informe final, publicado el 28 de agosto del 2003. 
Fue a partir de ese contexto que se realizaron entrevistas a algunas víctimas del conflicto armado interno del Perú. A continuación se presentan las dos entrevistas realizadas en Ayacuho, Perú.

\section{Entrevistado 1}

Abogado y policía que trabaja en Ayacucho, por su seguridad pide no tomar fotos ni registrar su nombre -no está autorizado para dar algún tipo de declaración- puesto que todavía forma parte de la institución policial, pero él ha sido una víctima de esta en determinadas ocasiones porque ha estado -incluso- privado de la libertad, se le han imputado cargos por ejecuciones extrajudiciales sin pruebas suficientes, ha quedado absuelto de todo. Cuando él, respecto al conflicto armado en el Perú, manifestó:

Para empezar, el conflicto armado que se vivió en el Perú fue una consecuencia de un grupo demente bastante desquiciado, podría yo llamarlo, por cuanto quería tomar poder, pero mediante las armas; una situación que en el siglo XX ya no es permitido, no era permitido, por cuanto existen otros medios democráticos para poder tomar el poder. Sin embargo, este grupo demencial, como le vuelvo a repetir, optó por esa opción, por una ideología implantada de otro sitio hacia el Perú, acomodada o acondicionada con un denominado pensamiento Gonzalo, que fue pues calando en los cerebros de los jóvenes y bueno..., y se enfrentaron al Estado; un Estado que no estaba preparado para enfrentar una guerra subrepticia, una guerra desde el anonimato que practicaba Sendero Luminoso, porque Sendero Luminoso atacaba a traición, daba sorpresa, no atacaba de frente, no vestían un uniforme, no se identificaban como guerrilleros, aunque ellos se autodenominan guerrilleros cuando no cumplen los requisitos, los principios de una guerrilla. La guerrilla tiene que ser uniformada, tiene que tener un representante y una serie de requisitos, lo cual no cumplían.
Y ahí queda pues establecido que Sendero Luminoso es un grupo criminal, volviendo al tema de que Perú ha sido un Estado que no se ha preparado para este tipo de guerra, por medio de quienes, pues de su fuerza armada y de sus fuerzas policiales, en ese entonces la guardia civil, la policía de investigaciones y la guardia republicana. La policía por su parte, estaba pues defendiendo sus especialidades, cada una, cada institución, estaba pues para enfrentar lo que es este, el tema delincuencial común, y las fuerzas armadas siguen estando un poco atadas con personal y logística, pero era pues un tema para enfrentar una guerra convencional, una guerra que se declaraba, una guerra donde uno sabe quién es el enemigo, pero en ese entonces no se sabía, entonces ha sido un problema para quienes de repente hemos vestido uniforme y nos ha tocado prestar servicio en la zona de emergencia, hacer frente a ese tipo de movimiento armado, de terrorismo, de delincuencia, no que hay otro aquí porque nunca se ha visto. (entrevista personal, Ayacucho, Perú, 23 de septiembre del 2017)

Luego de lo que manifestó el entrevistado sobre el conflicto armado en el Perú con el grupo armado ilegal Sendero Luminoso, se le preguntó sobre las acciones que el Estado puso en pie para contrarrestar las consecuencias del conflicto y la puesta en marcha de algún tipo de modelo de justicia transicional:

[...] en esa confrontación que ha existido lógicamente hay que saber reconocer, dado a que tanto las fuerzas no han estado preparadas, ni el Estado mismo, entonces ha habido excesos y lógico, por ello la Comisión de la Verdad y la Reconciliación, de cierto modo hay un inicio, ha servido para develar cierta verdad, pero que no ha sido del todo, ese ha sido el error de la Comisión, que solamente se ha dedicado a investigar, a recibir testimonios, pero solamente para perseguir y atacar a los miembros de las fuerzas, que si bien es cierto, han 
cometido violación de derechos humanos y merecen ser castigados, pero de otra parte, también debió investigarse, recogerse testimonios con relación, pues a los senderistas que cometieron atrocidades en agravio, pues de estos pueblos de la serranía, no se ha develado, se le ha atribuido las muertes, los daños irreparables ocasionados al Perú solamente [a] los mandos, a los líderes , al partido, en forma genérica, pero no se ha individualizado, como sí ha ocurrido por ejemplo, en el caso de los miembros de las fuerzas del orden, que por ahí han estado involucrados en violación de derechos humanos y se han identificado desde el jefe hasta el último soldado y a todos se les ha sancionado, en cambio, en el caso de Sendero pareciera que ha tenido una protección por parte de la Comisión de la Verdad y la Reconciliación. (entrevista personal, Ayacucho, Perú, 23 de septiembre del 2017)

Según lo manifestado por el entrevistado, en Perú se han centrado en uno de los objetivos de la justicia transicional, que es el esclarecimiento de la verdad a partir de la figura de la Comisión de la Verdad y la Reconciliación, que a su modo de ver, su labor se encuentra parcializada porque se ha centrado en cumplir funciones meramente de investigación y descripción, lo que ha posibilitado iniciar juicios penales contra las fuerzas militares pervanas, cosa que no ha sido tan marcada con referencia a las indagaciones relacionadas con Sendero Luminoso, lo cual expresa una posición desigual de la Comisión de la Verdad y la Reconciliación frente a los actores del conflicto:

Eso a nosotros al menos como fuerzas del orden, como miembros, si no parte de la fuerza del orden que hemos vivido en zona de emergencia, hemos visto pues esa situación, estamos imposibilitados de hablar y de prestar declaraciones, de mostrar nuestro rostro y de repente por ello, no hay quien defina a las fuerzas del orden y nadie niega de que se tenga que administrar justicia y si alguien cometió violación de derechos humanos, que tenga que pagar, nadie lo niega, nadie lo puede evitar, eso es lo justo, porque las víctimas, los familiares necesitan conocer la verdad y necesitan pues justicia, que se administre en su totalidad. Pero como vuelvo a repetir, la Comisión de la Verdad se ha preocupado [por] buscar una verdad a medias, la verdad solamente tiene un lado, una cara de la moneda, la otra no se conoce. Solamente se ha imputado la violación de derechos humanos, muertes, atentados, aniquilamientos selectivos, justicia popular ejercitada en distintos pueblos de forma genérica, por eso consideramos que es una Comisión de la mentira o en su defecto, es una Comisión de una verdad a medias y que no ha buscado la reconciliación sino que ha buscado un enfrentamiento, ha utilizado esta Comisión no para las facultades que se le han otorgado, no, los presupuestos, el dinero que se le ha dado para perseguir y para castigar únicamente a militares a policías, esa es la verdad. (entrevista personal, Ayacucho, Perú, 23 de septiembre del 2017)

Cuando el entrevistado hizo referencia a la necesidad de hacer justicia y que se haga una efectiva reparación a las víctimas y a sus familiares dijo:

[...] nadie niega de [sic] que se tenga que administrar justicia y si alguien cometió violación de derechos humanos, que tenga que pagar, nadie lo niega, nadie lo puede evitar, eso es lo justo, porque las víctimas, los familiares necesitan conocer la verdad y necesitan pues justicia [...] (entrevista personal, Ayacucho, Perú, 23 de septiembre del 2017)

Cuando se le preguntó sobre las acciones de reparación a las víctimas en Perú y la situación de seguridad en el país frente a otras coyunturas, expresó:

Es bien triste y doloroso, también hay mucha gente que ha sufrido, civiles que han estado entre dos fuegos, entre lo que es la represión por 
parte de las fuerzas armadas, la policía que no sabía cómo actuar en ese entonces, no había sido formad[a] para enfrentar este tipo de guerra, de terrorismo y bueno, por otro lado Sendero estaba en medio del comunero, el poblador, el campesino sufrió bastante y esas personas -con mayor razón- deben ser, este, reparados, resarcidos por todo el daño que se les ha ocasionado.

Así como con el tema de la corrupción, me parece que se avecina una situación pero terrible, no de repente como Sendero, pero algún movimiento, porque verdad que la corrupción que está generalizándose en el Perú, pese al desarrollo que está logrando, pero hay bastante corrupción, me pareciera de que por ahí va a haber un movimiento bastante fuerte y de repente esto va a generar conflicto, enfrentamiento entre peruanos, porque hay bastante corrupción [...]

Yo de verdad que agradezco a ustedes, pocas veces tengo oportunidad de conversar así, a veces cuando todos conversamos, pero así no más, no converso, duele un poco recordar porque he estado un año y medio en la cárcel [el entrevistado derramó lágrimas en este punto], un proyecto de vida truncado, tuve que empezar de cero. (entrevista personal, Ayacucho, Perú, 23 de septiembre del 2017)

\section{Entrevistado 2}

Abogado y policía. La entrevista realizada se centró en la reparación a las víctimas del conflicto armado y en la labor de la Comisión de la Verdad y la Reconciliación en materia de investigación. Con respecto al tema de la reparación integral a las víctimas expresó:

En relación [con el] derecho a la educación y la reparación integral de las víctimas, se tiene en Ayacucho escuelas unidocentes y multigrados donde estudian niños de primero hasta sexto grado de primaria en un aula y tienen un solo profesor, o sea, ¿de qué reparación podemos hablar frente a ellos? O sea, en pleno siglo XXI hay pueblos que viven en estado de emergencia, qué justicia, de qué reparación podemos hablar cuando se siguen vulnerando los derechos.

Muchas víctimas tienen familiares desaparecidos desde 1984, en el caso mío, un hermano mayor cuando yo tenía once años y él tenía catorce años, ha sido desaparecido un 29 de marzo 1984, hasta el día de hoy no sabemos dónde está, cómo lo han asesinado y no ha llegado ningún tipo de reparación a mi familia. Le seguimos buscando y junto con él han desaparecido treinta y dos personas. De las treinta y dos personas, niños o personas bastantes mayores, esta es la relación de todos los desaparecidos (el entrevistado se expresa con dolor], aparece inclusive en redes sociales.

Estas desapariciones no han estado incluidas en el informe de la Comisión de la Verdad, porque la Comisión de la Verdad, como lo ha dicho desde su posición de policía, es un informe de las ONG en el Perú, o de los que se han constituido en este, para recibir los millones de soles que no ha llegado ni un solo centavo a las verdaderas víctimas, porque mira, mis padres ha[n] sido víctimas directos. Es decir, primero porque han desaparecido sus hijos, segundo porque han sido desplazados del campo. Solo han recibido una constancia nada más, y nunca recibieron absolutamente nada. (entrevista personal, Ayacucho, Perú, 23 de septiembre del 2017)

En ese sentido, el entrevistado 2 se refiere a la ineficacia de las acciones de reparación por indemnización o restitución de tierras que han tratado de hacer en el Perú con las víctimas del conflicto armado entre el Estado y Sendero Luminoso, lo que evidencia que no es suficiente hablar de un tipo de justicia meramente retributiva. Un tipo de justicia restaurativa es necesaria: 
Entonces del cien por ciento, el noventa y seis por ciento solamente ha recibido un papel y solamente el uno por ciento, pero que no fueron víctimas, ni el terrorismo de la fuerza armada, sino era como lo había dicho el amigo policía, eran terroristas que tenían acceso a la Comisión de la Verdad y a todas esas ONG. Sí, o sea recibían productos alternativos que no han funcionado, no porque dentro de reparaciones que era cultivar hortalizas y con hortalizas no vas a sacar a nadie del tema pobreza, o era engañar a la gente con los programas sociales que existen] en abundancia en Ayacucho, pero no llega a las víctimas, o sea no llega a la parte rural, se ha quedado en la ciudad, porque son programas para los medios de comunicación, son programas para la televisión, para el periódico, para las redes sociales, pero no [para] los que han sido víctimas en el sentido estricto.

Se han implementado medidas como continuar denunciando como civiles estos hechos, casos que nosotros hemos puesto a conocer desde Ayacucho como profesional es del Derecho. Es porque no queremos que se invisibilice la vulneración a los derechos de las víctimas, como en los años ochenta, porque de los años ochenta definitivamente, si tú ponías en conocimiento público estos casos, te identificaban como activo de Sendero Luminoso; en un momento nos han llamado abogados de Sendero Luminoso, a pesar de que no teníamos ninguna relación. Y lo otro es hacer ver de [sic] que hoy en el siglo XXI, o sea, Sendero ideológicamente no existe, Sendero ideológicamente ha sido derrotado. Es claro que estos grupos ilegales se constituyen por ausencia del Estado en los territorios. (entrevista personal, Ayacucho, Perú, 23 de septiembre del 2017)

\section{La voz de víctimas del conflicto en Colombia}

El conflicto armado interno en Colombia es uno de los más antiguos, cuenta con más de sesenta años de lucha en los que se han establecido históricamente, tres oleadas de violencia según Pécault (2017): 1) primera ola de violencia de 1930 a 1948; 2) segunda ola de violencia entre 1950 y 1990; y 3) la tercera ola de violencia de 1990 a la actualidad.

En ese sentido, se señalan algunos de los procesos de paz vividos en Colombia, el primero con los paramilitares, miembros de las AUC, cuyo resultado fue la Ley de Justicia y Paz, Ley 975 del 2005 durante el gobierno de Álvaro Uribe Vélez, y el proceso de paz con el grupo guerrillero de las FARC-EP, cuyo resultado fueron los acuerdos de paz en la HabanaCuba, materializados a partir de la Jurisdicción Especial para la Paz (JEP) mediante el Acto legislativo 01 del 2017, la Ley 1820 del 2016, los Decretos 277 del 2017 y Decreto 1269 del 2017. En materia de reparación para las víctimas del conflicto armado se promulgó la Ley 1448 del 2011.

En el caso de Colombia fue difícil obtener dos entrevistas con víctimas del conflicto armado. Se obtuvo solo una entrevista que, a solicitud de la persona víctima se anexa en su totalidad, situación que no es ajena ni se sale del formato del presente documento, dado que no es un artículo científico. Las preguntas versan sobre la historia de vida de la entrevistada con relación al conflicto armado, su condición de víctima en el marco del conflicto armado y el impacto de la implementación del modelo de justicia transicional para las víctimas.

\section{Entrevistada}

Mujer afrodescendiente, diseñadora de modas, líder social y comunitaria en materia de derechos humanos, trabaja con su Fundación en la ciudad de Cali, Valle del Cauca. Ha sido víctima directa del conflicto armado en Colombia, varios de sus familiares han sido asesinados, entre ellos, uno de sus hermanos y su padre; en estos momentos se encuentra con protección especial. Accede a realizar esta entrevista porque acepta compartir su experiencia como víctima del 
conflicto armado y dar a conocer su labor en defensa de las de los derechos de las víctimas. Por razones de seguridad no se revela su identidad, pero ella autorizó la publicación de su entrevista completa:

[Pregunta]: ¿Cómo incidió el conflicto armado de nuestro país de forma negativa y positiva en su proyecto de vida?

[R/Negativa]: El conflicto destruyó parte de mi vida, cuando asesinaron a mi padre, el haber sufrido abuso sexual, ver morir familiares, amigos y demás conocidos, igualmente salir con mi familia, dejando mi tierra, mi cultura, mi identidad, entre otras (...) Llegar a Cali y pasar todas las necesidades que nunca esperé vivir, recibir humillaciones, llorar por sentirme incapaz de poder sostener y cuidar a mis hijos, tener temor que me asesinen o en su efecto a mis hijos, vivir con miedo, continuar perdiendo mis seres queridos, como el asesinato de [nombre reservado], no poder olvidar todo esto que me ha causado daño.

[R/Positiva]: Aprendí a ser fuerte, he conocido muchas personas valiosas que me ayudan a nivel personal, también a construir procesos en [aras de un] beneficio colectivo, trazarme metas, visionar y emprender, proyectar mi formación profesional, hablar en público, en fin, descubrir cualidades en mí que nunca me imaginé tener, ser perseverante y constante, llevar la voz de mi gente a escenarios internacionales para que conozcan lo que vivimos las comunidades afrodescendientes, afectadas en el marco del conflicto, pero también la afectación de un sistema estructural histórico, sin que el gobierno tome las acciones necesarias para evitar el exterminio de mi pueblo.

(Pregunta): ¿Se considera víctima del conflicto armado en Colombia?, ¿sí o no y por qué?
[Respuesta]: Me considero víctima del conflicto armado por los hechos violentos que viví como persona, pero también, siendo parte de una comunidad, que irrumpieron mi forma de vida en contra de mi voluntad, por actores ilegales y legales armados, dejándome secuelas irreparables, con afectaciones psicológicas, reconocido en la Ley 387/97, Ley 1448 y Decreto ley 4635 de 2011 y demás normas nacionales e internacionales que refieren a violación de DDHH y el DIH.

[Pregunta]: ¿Te has beneficiado del modelo de justicia transicional en materia de reparación integral y la no repetición en Colombia?

[Respuesta]: El beneficio que he recibido en el marco de la justicia transicional es la vivienda y cinco millones quinientos mil pesos de compensación económica en el año [sic] 2015, por desplazamiento forzado. En materia de las garantías de no repetición; el gobierno no me cumplió, porque la vivienda debí abandonarla por la situación de amenazas e intento de asesinato en el lugar que me fue entregada, y el recurso económico que debía utilizar para proyecto o estudio, lo utilice para pagar arrendamiento. No han restituido mis derechos étnicos territoriales, porque no hay garantías para volver a mi lugar de origen y en Cali, [que] es una ciudad que me gusta, me siento bien, pero continúo recibiendo amenazas que no me permiten llevar una vida normal. No puedo decir o sentirme beneficiaria del modelo de justicia transicional porque no me han restablecido mis derechos en cuanto se refiere la misma Ley 1448 o Decreto ley 4635 de 2011 (medidas de satisfacción, rehabilitación, restitución, indemnización administrativa y garantías de no repetición].

[Pregunta]: ¿Cuál ha sido tu aporte al proceso de construcción de paz? 
[Respuesta]: Mi aporte para la construcción de paz lo realizo desde mi participación en escenarios de construcción de propuestas que conlleven a [sic] resarcir el daño causado, a [sic] no llenar mi corazón de odio para replicar maldad, trabajar en articulación con otras víctimas y personas en general, para el beneficio colectivo. Para la lograr la paz, siempre he considerado que independiente del horror que vivimos, debemos ser las víctimas [las] que jalonemos los procesos que conlleven a [sic] construir en medio de las diferencias, porque conocemos el dolor, en toda magnitud, por estarazón no quiero que continúe la guerra en Colombia. Y estar en estos procesos es una medida de satisfacción y resiliencia que me llena de fuerza, y la razón de despertarme todos los días con la necesidad de seguir construyendo, logrando hacer de nuestro país, el mejor lugar para vivir.

(entrevista personal, Santiago de

Cali, 27 octubre de 2017 )

\section{Conclusión}

Cada conflicto armado interno $u$ otra forma de ejercicio de violencia como las dictaduras, tiene sus especificidades y dinámicas propias, por eso es importante que los Estados propendan por implementar un modelo de justicia transicional integral en el que no pierdan la perspectiva del análisis del contexto y de los escenarios de participación en el que las víctimas puedan ser reconocidas y efectivamente reparadas. No es suficiente centrar los esfuerzos en un tipo de justicia retributiva si no se ha pensado en un tipo de justicia restaurativa, en la que se debe pensar en las víctimas y los actores del conflicto de manera reparadora y reconciliatoria.

Particularmente, los argentinos necesitan reconciliarse como país, la idea es que la paz debe remitir a que estos procesos de restauración y perdón tienen que ser pedagógicos y didácticos para reconciliarse consigo mismo, con el otro, con la madre tierra y con Dios.

En el caso del Perú se han mostrado avances en los mecanismos del modelo de Justicia Transicional en algunos territorios como en su capital. En otros con alto impacto del conflicto armado como Ayacucho, se evidencia a través de la voz de las víctimas un abandono del Estado desde el esclarecimiento de la verdad, la justicia y la reparación integral.

Con respecto a nuestro país y escuchando la voz de las víctimas, se aprecia un mínimo avance en la implementación de los mecanismos de un tipo modelo de Justicia Transicional de corte reparativo, un ejemplo de ello, es la Ley 1448 del 2011, por la cual se dictan medidas de atención, asistencia y reparación integral a las víctimas del conflicto armado interno, con la que se han tenido traspiés en términos estructurales, económicos y políticos para su efectivo cumplimento, en especial, sobre sus alcances en la garantía y protección de los derechos a la verdad, la justicia, la reparación y las garantías de no repetición para las víctimas. Por tal razón, la Corte Constitucional mediante la Sentencia C-588/19, establece que el Congreso de la República y quien ejerce el poder ejecutivo en el país deben realizar todas las acciones pertinentes para extender la vigencia de la Ley $1448 \mathrm{del}$ 2011, por lo menos diez años más, en pro de la garantía y el respeto a los Derechos de las víctimas del conflicto armado en Colombia. Esto para continuar con los procesos en la restitución de tierras, la reparación integral con un enfoque de género, psicosocial y diferencial, el esclarecimiento de la verdad, la memoria histórica del conflicto armado en los territorios y sus consecuencias, la resiliencia de las comunidades y su reinvención hacia nuevos proyectos, y la justicia especial para la paz (JEP). 


\section{Referencias}

Centro Internacional para la Justicia Transicional (ICT)) (2018). ¿Qué es la Justicia Transicional? https:// www.ictj.org/es/que-es-la-justicia-transicional

Patierno, N., y Martino, S. M. (2016). Historia y memoria en Argentina: análisis de la dictadura militar (1976-1983) a través del cine como estrategia de intervención alternativa en el escenario escolar. Revista Colombiana de Educación, (71), 279-297. https://doi. org/10.17227/01203916.71rce279.297
Pécaut, D. (2017). En busca de la Nación colombiana. Editorial Debate.

United States Institute of Peace (USIP). (2017). Los actores políticos e institucionales. https:// www.usip.org/sites/default/files/file/resources/collections/commissions/Peru01-Report/ Peru01-Report_Vol3.pdf 